\title{
Yttrium-Catalysed Dehydrocoupling of Alanes with Amines
}

\author{
Adi E. Nako, Sarah J. Gates, Nicole Schädel, Andrew J. P. White and Mark R. Crimmin* \\ Received (in $X X X, X X X)$ Xth $X X X X X X X X X 20 X X$, Accepted Xth $X X X X X X X X X 20 X X$ \\ DOI: $10.1039 / b 000000 x$
}

\begin{abstract}
We report $\left[\mathrm{Y}\left\{\mathrm{N}\left(\mathrm{SiMe}_{3}\right)_{2}\right\}_{3}\right]$ as a precatalyst for the dehydrocoupling of sterically demanding amines with $\beta$ diketiminate stabilised aluminium dihydrides. While simple anilines readily undergo $\mathrm{Al}-\mathrm{H} / \mathrm{N}-\mathrm{H}$ dehydrocoupling under thermal conditions, catalytic methods are required to achieve 10 reasonable rates of reaction for ortho-substituted anilines or hindered aliphatic amines.
\end{abstract}

The drive to control the rate of hydrogen release from amineborane has given rise to a number of mechanistically diverse catalyst systems capable of the dehydrocoupling of protic 15 and hydridic substrates. ${ }^{1}$ While new catalysts for amine-borane (or phosphine-borane) dehydrogenation continue to attract attention, ${ }^{2}$ in the past few years related methods for heteroatomheteroatom bond formation by dehydrocoupling have emerged. ${ }^{3}$ For example, the catalytic reaction of amines with silanes 20 provides an atom-efficient route to form nitrogen-silicon bonds and incorporate silyl-protecting groups into organic molecules. ${ }^{4}$ Although a number of precatalysts have been developed that are capable of catalysing the release of multiple equivalents of $\mathrm{H}_{2}$ from $\mathrm{H}_{3} \mathrm{~N} \cdot \mathrm{BH}_{3},{ }^{1}$ the formation of unsaturated products or 25 intermediates, such as silylimines $\left[\mathrm{R}_{2} \mathrm{Si}=\mathrm{NR}\right]$, from the dehydrocoupling of $\mathrm{R}_{2} \mathrm{SiH}_{2}$ and $\mathrm{H}_{2} \mathrm{NR}$ are rare. ${ }^{5}$

$$
\begin{gathered}
n \mathrm{H}_{3} \mathrm{~N}-\mathrm{BH}_{3} \stackrel{\text { Catalyst }}{\longrightarrow}\left[\mathrm{H}_{2} \mathrm{NBH}_{2}\right]_{n}+n \mathrm{H}_{2} \\
\mathrm{RNH}_{2}+\mathrm{H}_{3} \mathrm{SiR} \stackrel{\text { Catalyst }}{\longrightarrow} \mathrm{RNH}-\mathrm{SiH}_{2} \mathrm{R}+\mathrm{H}_{2}
\end{gathered}
$$

30 Fig. 1. The dehydrogenation of amineboranes and the dehydrocoupling of amines with silanes.

Amine-adducts of $\mathrm{AlH}_{3}$ have been proposed as hydrogen storage materials, and aluminium amides themselves may act as single source precursors for the chemical vapour deposition of 35 aluminium nitride. ${ }^{6-7}$ Although the dehydrocoupling (or protonolysis) of aluminium hydrides with amines is a common method to make Al-N bonds, these reactions can suffer from slow reaction rates and often salt-metathesis methods are preferred. ${ }^{8}$ For substrates containing more than one Al-H bond 40 achieving a selective reaction is also a potential problem. Catalytic approaches to the dehydrocoupling of amines and alanes offer an opportunity to address the issue of selectivity while vastly increasing reaction rates, to the best of our knowledge catalysts for this reaction remain unreported. Herein 45 we report our initial findings on the thermal and catalytic dehydrocoupling of amines with sterically demanding alanes.

Thermal Dehydrocoupling of Anilines with Alanes: The reaction of 4-fluoroaniline with $\mathbf{1 a - b}$ in toluene gave the corresponding mono-substitution products in good yield within ${ }_{50} 2 \mathrm{~h}$ at $25{ }^{\circ} \mathrm{C}$. Variation of the substrate to aniline or $2,4,6-$ trifluoroaniline had little effect on the efficiency of the reaction with 1a. The corresponding aluminium amides 2a-d were isolated in $39-95 \%$ yield following preparative scale experiments. The variation in the isolated yields is more likely a consequence of the 55 conditions of crystallisation rather than the efficiency of thermal dehydrocoupling.

Table 1. The thermal dehydrocoupling of sterically demanding alanes with anilines.

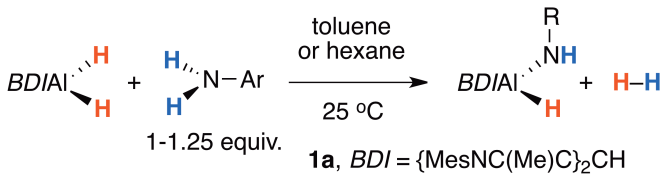

$$
\begin{aligned}
& \text { 1b, } B D I=\{2,6 \text {-xylyINC(Me)C }\}_{2} \mathrm{CH}
\end{aligned}
$$$$
\text { 1c, } B D I=\left\{2,6-\mathrm{DippNC}(\mathrm{Me}) \mathrm{C}_{2} \mathrm{CH}\right.
$$

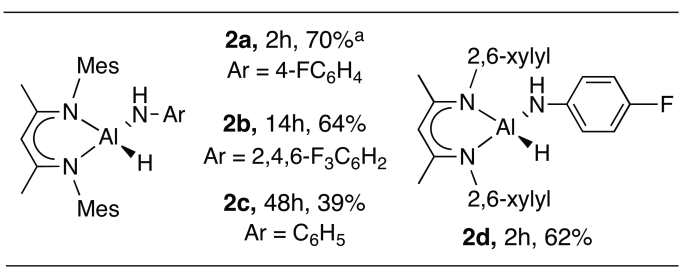

aisolated yields

${ }_{60}$ The reaction scope was extended to include to the 5-coordinate aluminium dihydride, 1d (Scheme 1). ${ }^{9}$ Reaction with 2 equiv. of 4-fluoroaniline proceeds rapidly at $25{ }^{\circ} \mathrm{C}$ to yield 3 . The reaction is not selective and attempts to modify the conditions to isolate the hydrido/amide intermediate failed. Although we have ${ }_{65}$ previously demonstrated that $\mathbf{1 d}$ remains 5-coordinate in solution, ${ }^{9}$ in the current case, we propose that the dissociation of the pendant amine becomes favourable following the first Al-N bond formation. As a result the rate of the second dehydrocoupling becomes comparable with the first and the 70 reaction is no longer selective. 
(a)

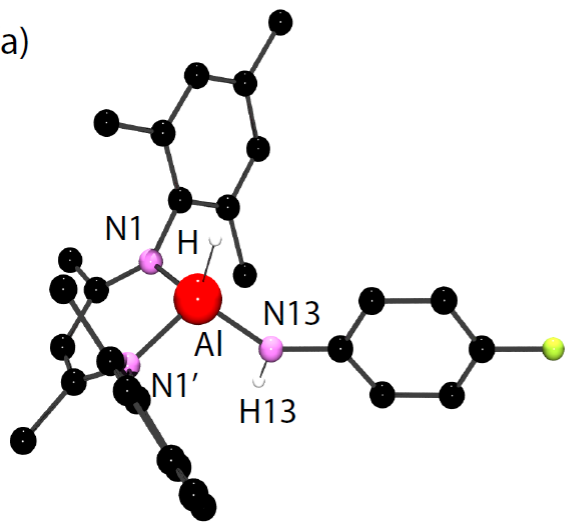

(b)

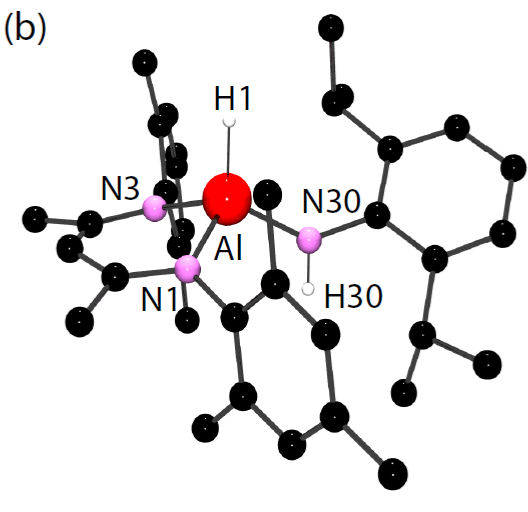

(c)

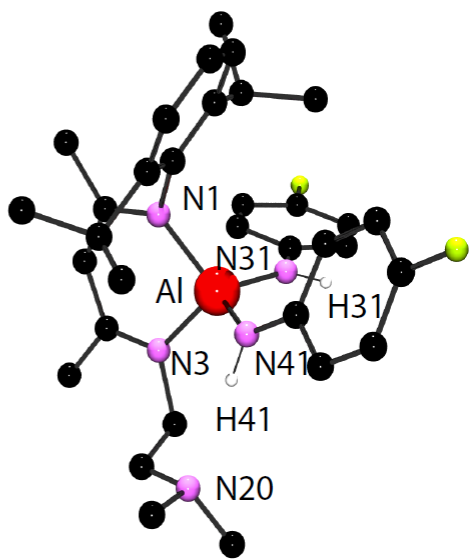

Figure 2. The crystal structure of (a) 2a, (b) $4 \mathbf{b}$ (disordered toluene molecule omitted for clarity), and (c) 3. Selected bond angles $\left({ }^{\circ}\right)$ and bond lengths $(\AA)$ : 2a, Al-N1 1.8893(11), Al-N13 1.81.32(16), N1-Al-N1'96.52; 4b, Al-N1 1.8951(16), Al-N3 1.9021(15), Al-N30 1.8182(16), N1-Al-N3 95.55(7); 3, Al-N1 1.9084(17), Al-N3 1.905(2), Al-N31 1.7998(19), Al-N41 1.805(19), N1-Al-N3 94.17(8).

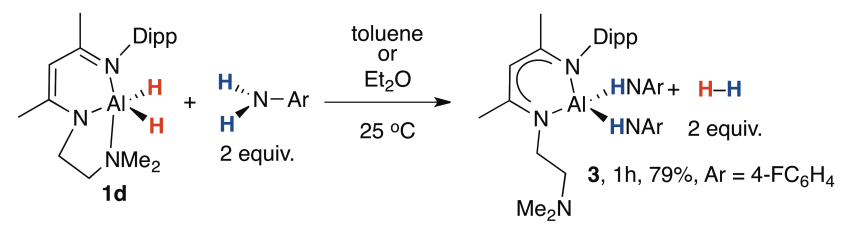

Scheme 1. The thermal dehydrocoupling of a 5-coordinate alane with $p$ fluoroaniline.

In order to test this hypothesis, ${ }^{1} \mathrm{H}-{ }^{15} \mathrm{~N}$ HMBC experiments 10 were conducted on $\mathrm{C}_{6} \mathrm{D}_{6}$ solutions of $\mathbf{1 d}, \mathbf{3}$ and a reaction mixture containing the hydrido/amide intermediate 3 ' at $298 \mathrm{~K} .{ }^{15} \mathrm{~N}$ chemical shifts of $\delta=28.1,29.8$ and 22.4 ppm were recorded for the $\mathrm{NMe}_{2}$ group of $\mathbf{1 d}, \mathbf{3}$, and $\mathbf{3}$ respectively. While these data are consistent with amine dissociation in $\mathbf{3}$, the difference between 15 the chemical shifts of the $\beta$-diketiminate nitrogens $\Delta \delta=67.8$, 59.2 and $4.2 \mathrm{ppm}$ of $\mathbf{1 d}, \mathbf{3}$ ' and $\mathbf{3}$ respectively, provides direct evidence for a dramatic change in the electronic structure of the ligand. Hence, 1d and 3' possess a trigonal bipyramidal structure with the equatorial and axial positions being magnetically and 20 chemically distinct while $\mathbf{3}$ possess a four-coordinate geometry. In combination with an X-ray crystallography study (Figure 2) these data show that the pendant amine of $\mathbf{3}$ not coordinated to $\mathrm{Al}$ either in solution or the solid-state. While 3' appears to remain 5coordinate in solution at $298 \mathrm{~K}$, it can be expected that amine 25 dissociation will more facile than that of $\mathbf{1 d}$ and open up the coordination at $\mathrm{Al}$, favouring a second dehydrocoupling.

Catalytic Dehydrocoupling: Attempts to extend the scope of the thermal reaction to hindered aliphatic amines $(\mathrm{pKa} \sim 40-45)$ or ortho-substituted anilines $(\mathrm{pKa} \sim 30)$ failed to proceed 30 selectively at useful reaction rates. For example, the reaction of an excess of tert-butylamine with 1a in $\mathrm{C}_{6} \mathrm{D}_{6}(0.1-0.2 \mathrm{M}$ in 1a) only reached completion after $12 \mathrm{~d}$ at $80{ }^{\circ} \mathrm{C}$.
Table 2. $\left[\mathrm{Y}\left\{\mathrm{N}\left(\mathrm{SiMe}_{3}\right)_{2}\right\}_{3}\right]$ catalysed dehydrocoupling of 35 sterically demanding alanes with ortho-substituted anilines and amines.

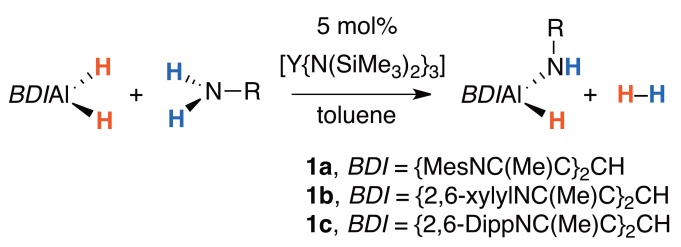

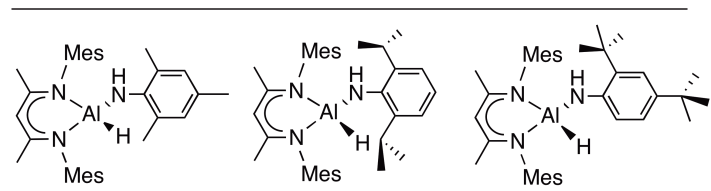

4a, $2 \mathrm{~h}, 70 \% \mathrm{a}$ $\left(6 \mathrm{~d}, 80^{\circ} \mathrm{C}, 6 \%\right)^{\mathrm{b}, \mathrm{c}}$<smiles></smiles>

$4 d, 1 \mathrm{~h}, 64 \% \mathrm{~d}$ $\left(12 \mathrm{~d}, 80^{\circ} \mathrm{C}, 86 \%\right)^{\mathrm{d}}$ 4b, $2 \mathrm{~h}, 89 \%$ $\left(8 \mathrm{~d}, 80^{\circ} \mathrm{C}, 0 \%\right)$<smiles>[H][Y]1(NC23CC4CC(CC(C4)C2)C3)C(C)=CC(C)N(C)N1C</smiles>

$4 \mathrm{e}, 2 \mathrm{~h}, 48 \%$ $\left(6 \mathrm{~d}, 80^{\circ} \mathrm{C}, 62 \%\right)$ 4c, $2 \mathrm{~h}, 64 \%$ (1d, $\left.80^{\circ} \mathrm{C}, 3 \%\right)$<smiles>CC1=CC(C)=C(N2CCCC2)N(C)N1C</smiles>

4f, 1 h, $66 \%$ $\left(17 \mathrm{~d}, 25^{\circ} \mathrm{C}, 95 \%\right)$

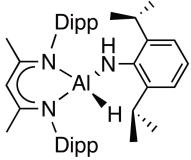

4g, $15 \mathrm{~h}, 87 \%$ $\left(1 \mathrm{~d}, 150^{\circ} \mathrm{C}, 1 \%\right)$<smiles>[CH][Al]1(Nc2ccc(F)cc2)N([Po])C(C)=CC(C)N1[Pb]</smiles>

4h, $1 \mathrm{~h}, 52 \%$ $\left(1 \mathrm{~d}, 80^{\circ} \mathrm{C}, 80 \%\right)^{\Theta}$

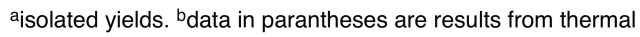
background reactions. cNMR scale yields. ${ }^{\mathrm{d}} 2.5$ - 5 equiv. of amine used. e $4: 1$ mixture of mono- and bis-dehydrocoupling

In contrast, at $25{ }^{\circ} \mathrm{C}$ with addition of $5 \mathrm{~mol} \%\left[\mathrm{Y}\left\{\mathrm{N}\left(\mathrm{SiMe}_{3}\right)_{2}\right\}_{3}\right]$ 40 vigorous gas evolution was observed. Monitoring the latter 
reaction by ${ }^{1} \mathrm{H}$ NMR spectroscopy revealed not only the formation of $\mathrm{H}_{2}(\delta=4.49 \mathrm{ppm})$ but complete and selective formation of $\mathbf{4 d}$ within 30 minutes at $25^{\circ} \mathrm{C}$. The catalyst loading could be lowered to $0.5 \mathrm{~mol} \%$ without a detrimental effect on the 5 yield or reaction time. These data allow a coarse estimation of a minimum catalyst TOF of $500 \mathrm{~h}^{-1}$ for this reaction; a value that compares favourably to that of $>1000 \mathrm{~h}^{-1}$ at $50{ }^{\circ} \mathrm{C}$ for boratabenzene yttrium alkyl catalysts employed for the dehydrogenation of dimethylamine-borane. ${ }^{10 \mathrm{c}}$ Scale up of this 10 reaction in toluene gave the product in a $64 \%$ isolated yield.

The catalytic dehydrocoupling of sterically demanding alanes can be generalised to a number of ortho-substituted anilines (Table 2, 4a-c, 4g) primary amines (Table 2, 4d-e) and a secondary amine (Table 2, 4f). ${ }^{\pi}$ It is noteworthy that rare-earth 15 bis(trimethylsilyl)amides have proven efficient catalysts for amine-silane dehydrocoupling, amine-borane dehydrogenation, and the dehydrocoupling of triphenylphosphonium methylide with phenylsilane. ${ }^{4,10,11}$ Furthermore, aluminium hydrides themselves have recently emerged as efficient catalysts for 20 amine-borane dehydrocoupling. ${ }^{12}$

In all cases, thermal control reactions show either trace or no conversion under the same conditions and require both elevated temperatures and extended reaction times to reach similar yields as the catalytic experiments (Table 2). For example, complex $\mathbf{4 g}$ 25 has been previously reported by $\mathrm{H}$. Roesky and co-workers and may be synthesized by the thermolysis of $\mathbf{1 b}$ in neat 2,6-di-isopropylaniline at $150{ }^{\circ} \mathrm{C}$ for $1 \mathrm{~h}$. Conducting this reaction in a flame-sealed NMR tube in toluene- $\mathrm{d}^{8}$ gave only trace conversion after $1 \mathrm{~d}$ at $150{ }^{\circ} \mathrm{C} .{ }^{13}$ With $5 \mathrm{~mol} \%\left[\mathrm{Y}\left\{\mathrm{N}\left(\mathrm{SiMe}_{3}\right)_{2}\right\}_{3}\right]$ the reaction 30 proceeds at $25{ }^{\circ} \mathrm{C}$ giving $4 \mathrm{~g}$ in $87 \%$ isolated yield, albeit with a longer reaction time of $15 \mathrm{~h}$ (Table $2, \mathbf{4 g}$ ). Under these catalytic conditions, hindered $2^{\circ}$ amines such as di-iso-propylamine and hexamethyldisilazane gave no reaction with 1a despite prolonged heating at $80^{\circ} \mathrm{C}$.

35 The reaction products have been characterised by multinuclear NMR and infrared spectroscopy and CHN analysis. Complexes 2a-d and 4a-h display Al-H stretches in the region of 1788-1875 $\mathrm{cm}^{-1}$, while in some cases $\mathrm{N}-\mathrm{H}$ stretches were observed between 3344-3449 $\mathrm{cm}^{-1}$ but these bands were often weak and broad. 40 Multinuclear NMR data supports the assignment and while the $\mathrm{Al}-\mathrm{H}$ resonances are observed as extremely broad peaks in the region of $\delta=3.0-5.0 \mathrm{ppm}$, the aliphatic $\mathrm{N}-\mathrm{H}$ protons of $\mathbf{4 d}$ and 4e demonstrate a ${ }^{3} J_{\mathrm{H}-\mathrm{H}}$ coupling to the $\mathrm{Al}-\mathrm{H}$ and resonate at $\delta=$ $0.56(\mathrm{~d}, J=3.6 \mathrm{~Hz})$ and $0.36(\mathrm{~d}, J=3.2 \mathrm{~Hz}) \mathrm{ppm}$ respectively.

${ }_{45}$ Complexes $\mathbf{2 a}, \mathbf{3}$ and $\mathbf{4 b}$ have been characterised by single crystal X-ray diffraction and while the metrical parameters do not warrant discussion it is noteworthy that the pendant amine of $\mathbf{3}$ is not coordinated to aluminium in the solid state.

In summary, we have reported $\left[\mathrm{Y}\left\{\mathrm{N}\left(\mathrm{SiMe}_{3}\right)_{2}\right\}_{3}\right]$ as a ${ }_{50}$ precatalyst for the dehydrocoupling of amines with sterically demanding alanes. Catalysis proceeds rapidly at $25{ }^{\circ} \mathrm{C}$ and is significantly more efficient than thermal methods. While these findings may open up new possibilities for the application of aluminium amides as materials precursors, as ligands for 55 transition metals, or as intermediates in catalysis, if a further catalytic dehydrogenation of the aluminium hydrido/amide complexes reported herein could be achieved it may generate a reactive 3 -coordinate aluminium imido, $B D I A l=N R .{ }^{8 b}$ This latter moiety has been proposed as an intermediate in intramolecular ${ }_{60} \mathrm{C}-\mathrm{H}$ activation and $[2+2]$ cycloaddition reactions. ${ }^{14-15}$

\section{Notes and references}

${ }^{a}$ Department of Chemistry, Imperial College London, South Kensington, London SW7 2AZ, U.K. Tel: +44(0)2075942846; E-mail: m.crimmin@imperial.ac.uk

$65 \uparrow$ Electronic Supplementary Information (ESI) available: Including full experimental procedures, X-ray crystallography data and details of calculations. See DOI: 10.1039/b000000x

I General experimental procedure for catalytic dehydrocoupling: In a glovebox, the alane $(0.33 \mathrm{mmol})$ and $\left[\mathrm{Y}\left\{\mathrm{N}\left(\mathrm{SiMe}_{3}\right)_{2}\right\}_{3}\right](0.016 \mathrm{mmol})$ 70 were weighed out into a $20 \mathrm{~mL}$ glass scintillation vial. Dry toluene or diethyl ether $(2 \mathrm{~mL})$ was added followed by addition of the amine $(0.33$ mmol). Vigorous effervescence was observed and the vial was sealed. The reaction mixture was left for $0.5-15 \mathrm{~h}$ at $25{ }^{\circ} \mathrm{C}$ before the mixture was passed through glass fibre filter paper and the solvent removed under 75 reduced pressure. The crude reaction mixture was then either recrystallized or washed with cold hexane to give the pure product (48$89 \%$ yield).

1 (a) T. J. Clark, K. Lee and I. Manners, Chem. Eur. J. 2006, 12, Organomet. Chem. 1998, 42, 363.

2 (a) M. C. Denney, V. Pons, T. J. Hebden, D. M. Heinekey, K. I. Goldberg, J. Am. Chem. Soc. 2006, 128, 12048. (b) C. A. Jaska, I. Manners, J. Am. Chem. Soc. 2004, 126, 9776.

3 (a) E. M. Leitao, T. Jurca, I. Manners, Nature Chem. 2013, 5, 817. (b) R. J. Less, R. L. Melen, D. S. Wright, RSC Advances 2012, 2, 2191.

4 (a) W. Xie, H. Hu, C. Cui, Angew. Chem., Int. Ed. 2012, 51, 11141; (b) M. S. Hill, D. J. Liptrot, D. J. MacDougall, M. F. Mahon, T. P. Robinson, Chem. Sci. 2013, 4, 4212; (c) F. Buch, S. Harder, Organometallics 2007, 26, 5132; (d) J. F. Dunne, S. R. Neal, J. Engelkemier, A. Ellern, A. Sadow, J. Am. Chem. Soc. 2011, 133, 16782.

5 Y. Chen, H. Song, C. Cui, Angew. Chem., Int. Ed. 2010, 49, 8958.

6 (a) D. J. Grant and D. A. Dixon, J. Phys. Chem. A, 2005, 109, 10138; (b) B. M. Wong, D. Lacina, I. M. B. Nielsen, J. Graetz and M. D. Allendorf, J. Phys. Chem. C, 2011, 115, 7778.

7 (a) F. C. Sauls and L. V. Interrante, Coord. Chem. Rev., 1993, 128, 193; (b) Y. Saito, Y. Sugahara and K. Kuroda, J. Am. Ceram. Soc, 2000, 83, 2436; (c) J. Khanderi, D. Rische, H. W. Becker and R. A. Fischer, J. Mater. Chem, 2004, 14, 3210; (d) U. Werner, Structure and Bonding, 2003, 105, 41.

8 (a) A. Y. Timoshkin, Coordination Chemistry Reviews, 2005, 249, 2094-2131; (b) J. Koller, R. G. Bergman, Organometallics 2010, 29, 3350. (c) A. Heine and D. Stalke, Angew. Chem., Int. Ed. 1992, 31, 854. (d) M. L. Montero, H. Wessel, H. W. Roesky, M. Teichert, I. Usón, Angew. Chem., Int. Ed. 1997, 36, 629.

9 A. E. Nako, S. J. Gates, A. J. P. White, M. R. Crimmin, Dalton Trans. 2013, 42, 15199.

10 For amine-borane dehydrogenation see (a) M. S. Hill, G. Kociok-Köhn and T. P. Robinson, Chem. Commun., 2010, 46, 7587; (b) P. Cui, T. P. Spaniol, L. Maron and J. Okuda, Chem. Eur. J., 2013, 19, 13437; (c) E. Lu, Y. Yuan, Y. Chen and W. Xia, ACS Catal., 2013, 3, 521.

11 A. E. Nako, A. J. P. White, M. R. Crimmin, Chem. Sci. 2013, $4,691$.

12 (a) H. J. Cowley, M. S. Holt, R. L. Melen, J. M. Rawson and D. S. Wright, Chem. Commun. 2011, 47, 2682. (b) M. M. Hansmann, R. L. Melen and D. S. Wright, Chem. Sci. 2011, 2, 1554. (c) R. J. Less, H. R. Simmonds, D. S. Wright, Dalton Trans. 2014, 43, 5785 . 
13 H. Zhu, Z. Yang, J. Magull, H. W. Roesky, H.-G. Schmidt and M. Noltemeyer, Organometallics 2005, 24, 6420.

14 For putatative three-coordinate $\mathrm{L}_{\mathrm{n}} \mathrm{Al}=\mathrm{NAr}$ see: (a) N. J. Hardman, C. Cui, H. W. Roesky, W. H. Fink and P. P. Power, Angew. Chem. Int. Ed. 2001, 40, 2172; (b) H. Zhu, J. Chai, V. Chandrasekhar, H. W. Roesky, J. Magull, D. Vidovic, H.-G. Schmidt, M. Noltemeyer, P. P. Power and W. A. Merrill, $J$. Am. Chem. Soc. 2004, 126, 9472; (c) H. Zhu, J. Chai, V. Jancik, H. W. Roesky, W. A. Merrill and P. P. Power, J. Am. Chem. Soc. 2005, 127, 10170

15 For an isolated four-coordinate $\mathrm{L}_{\mathrm{n}} \mathrm{Al}=\mathrm{NAr}$ see: J. Li, X. Li, W. Huang, H. Hu, J. Zhang and C. Cui, Chem. Eur. J. 2012, 18, 15263 . 